\title{
REVIEW
}

\section{A Review for Existing Complementary and Alternative Medical Therapies for Autism Spectrum Disorder}

\author{
Xinyi Yin* \\ Miss Hall's School, Pittsfield, 01202, MA, U.S.
}

\section{ARTICLE INFO}

Article history

Received: 28 July 2020

Accepted: 18 September 2020

Published Online: 30 October 2020

Keywords:

Autism

ASD

Intervention

Complementary and alternative medical therapies

\begin{abstract}
Autism Spectrum Disorder (ASD) has always been a frustrating disability for families and no official effective medical interventions has been found to cure this disorder yet. With more attention from the general public both nationally and internationally, more and more families and therapists showed preference to implement complementary and alternative medical (CAM) therapies. This review aims to provide more information about potential CAM that has been applied and their effectiveness.
\end{abstract}

\section{Introduction}

A utism Spectrum Disorder (ASD) is categorized as a type of developmental disability that is caused by a range of genetic mutations. This disorder may cause significant social, communication, and behavioral challenges which also vary for each individual. ASD has a growing prevalence that according to the Centers for Disease Control and Prevention (CDC), studies in Asia, Europe, and North America have identified individuals with ASD with an average prevalence of between $1 \%$ and $2 \%{ }^{[34]}$. A wide range of possible complementary and alternative medical (CAM) therapies have been developed since the last century, but their effectiveness is different for each situation and individual.
Various theories may be posed for single intervention, though more research and experiments may be required to certify its feasibility. Some CAM methods are more commonly used than others and those that have been frequently mentioned in studies and reviews are facilitated communication (FC), auditory integration training (AIT), heavy-metal chelation, secretin intervention, dietary intervention, dolphin-assisted therapy, musical therapy, and equine-assisted therapy.

\section{Facilitated Communication Training}

Facilitated communication starts with hand-over-hand support from the communicator as children fulfil tasks like multiple choice and fill-in-the-blanks of conversational

*Corresponding Author:

Xinyi Yin,

Miss Hall's School, Pittsfield, 01202, MA, U.S.;

Email:xinyi.yin@misshalls.org 
texts. Then the external support would fade and the tasks change from structured to unstructured conversations ${ }^{[5]}$. An increased capability of communication and social skills is expected from this process which enables autistic children to write and express themselves freely and logically. However, studies in the following years have proved that the results from the experiment in 1992 were not reproducible and controversial. According to a review by Braman and other researchers, cases in which $\mathrm{FC}$ is proven to be effective, the responses received from participants were merely naming responses that are frequently one word ${ }^{[7]}$. Experiments that have already been carried out usually consist of a limited number of participants, thus the results are not as convincing and further quantitative experiments may be required to certify the effectiveness of FC as an intervention. The American Speech and Hearing Association (ASHA) has also pointed out that FC is not a recommended way of as evidencedinterventions, as it fails to meet the scientific efficacy standard. Furthermore, the risk of misinterpretation is undeniable and exists even among people without communication or social disabilities, thus the benefits from FC may be overweight by its disadvantages ${ }^{[38]}$.

\section{Auditory Integration Training}

Auditory integration training required participants listening to pieces of modified music from headphones. This method was explicitly not recommended by ASHA due to its efficacy along with $\mathrm{FC}^{[38]}$. Experiment has also proven that the "change score" detected before and after AIT was not significant. For both parent-graded Aberrant Behavior Checklist Hyperactivity and parent Nisonger Child Behavior Rating Form Hyperactivity, the control group has more reduced score than the experimental group while the behavioral observation data for ear occlusion shows that behaviors have been increased after AIT. This experiment by Mudford showed that results from previous research proving AIT is effective is not replicable ${ }^{[22]}$.

\section{Heavy-Metal Chelation}

The toxicity of mercury has long been well known, but the relationship between $\mathrm{Hg}$ and ASD was also proposed. The amount of mercury in vaccines in early childhood was discovered exceeding the standard government safety guidelines. Phenomena such as symptoms shown shortly after immunization, the increasing ASD prevalence along with vaccination increase, the similar ratio in sex of individuals influenced and a high heritability rate trend long with genetic predisposition to mercury sensitivity at low doses ${ }^{[4]}$. Since mercury could be a potential cause for ASD, the commonly seen method of removing heavymetal from the bloodstream, chelation, is proposed as a treatment for ASD. However, this way of intervention may bring potential risk to autistic patients ${ }^{[38]}$ while no adequate previously peer-reviewed publications about the efficacy of chelation treatment have been published ${ }^{[16]}$. More quantitative research may be required to determine the safety and efficacy of heavy-metal chelation as an ASD CAM treatment.

\section{Secretin Intervention}

Researchers like Horvath claimed that according to the observations from three autistic children after secretin treatment, gastrointestinal symptoms may have some correlation with the pathogenesis of ASD and secretin, as a type of a gastrointestinal peptide hormone, may contribute to the autistic behaviors. In his experiment, scientists observed hypersecretion of pancreaticobiliary fluid as well as detected improvements in social ability, communication and language skills ${ }^{[13]}$. However, this result was overthrown by several later experiments and evaluations. A study in 2001 doubts the reproducibility of Horvath's results that 18 boys and 2 girls in the experiment showed neither significant improvement in language skills, nor in atypical behaviors and social skills ${ }^{[18]}$. Some may argue that the previous research may be limiting as it is a single-blinded, open-label pilot study, but beside the previous study, the seven randomized controlled trials by Krishnaswami do not show adequate evidence of effectiveness of secretin as a treatment for ASD ${ }^{[14]}$. Controversial results may demand further research to be carried out to testify the effectiveness for secretin interventions and it is undeniable that individual differences may influence the data.

\section{Dietary Intervention}

Some scientists suspect that food allergies and sensitivities are the causes for certain behavioral challenges for autistic individuals ${ }^{[38]}$. In White's review and according to other researchers, metabolites of gluten and milk may interfere with brain function that causes abnormal behaviors as casomorphins and gliadomorphins are produced and leak out influencing the central nervous system (CNS) ${ }^{[39]}$. The two substances mentioned wouldn't be hydrolyzed by proteolytic enzymes and thus stay in a relatively stable form and constantly affect the $\mathrm{CNS}^{[8]}$. Nevertheless, casomorphins can also be detected within the human cerebrospinal fluid (CSF) ${ }^{[26]}$. From Sun and Cade's experiments, one substance of this family, $\beta$-casomorphin-7, has triggered behavioral changes when 
injected into rats ${ }^{[35]}$. Another aspect of this treatment is the opioid excess theory, which explains that the behaviors found in autistic patients expresses the effect of opioids on human brain function ${ }^{[39]}$. Young animals like rats that have exposure to low doses of opiate drugs displayed some behavioral symptoms seen in autistic children, providing evidence to the above theory ${ }^{[27]}$. By implementing dietary intervention, gluten and casein containing foods are excluded and supplements such as peptidase enzymes would be induced to breakdown casomorphin and gliadorphin into smaller peptides that have no opioid activity ${ }^{[10]}$. According to White, there are Anecdotal reports and limited single blind studies report improved social, cognitive and communication skills in individuals with autism using dietary and enzyme therapy ${ }^{[39]}$. However, a double-blind randomized controlled trial that aims to testify the effect of enzyme therapy on autistic behaviors shows that there is no significant improvement observed from the participants ${ }^{[23]}$. Moreover, a review shows that in over half of the experiments between 1977 and 2010 on dietary treatment have multiple interventions practiced by participants, so it is also difficult to isolate the effect of a single intervention ${ }^{[44]}$. Thus, from all of the results above, the evidence is not enough to accurately evaluate the effectiveness of dietary intervention and more rigorously designed research is needed.

\section{Dolphin-Assisted Therapy}

Dolphin-assisted therapy includes both on dock and inwater sessions and interactions with dolphins would be considered rewards of operant conditioning. The program is supported by three theories: attention deficit hypothesis, operant conditioning, and interdisciplinary team model ${ }^{[24]}$. The attention deficit hypothesis suggests that individuals with mental retardation to learning are caused by a deficit of ability to capture relevant dimensions of stimuli instead of unable to process information ${ }^{[31]}{ }^{[43]}$. By assisting those individuals finding cues of stimuli and being exposed under that condition long enough, triggered learning behaviors may be observed ${ }^{[17][21]}$. This theory is later extended to neurological perspectives that attention deficit may also be caused by visual spatial frequency ${ }^{[29]}$ ${ }^{[32]}$, frontal lobe impairment ${ }^{[3]}{ }^{[12]}$, and neuronal size ${ }^{[40]}$. Operant research has long been discovered and applied which turned out to be relatively effective among all methods for individuals with severe disabilities ${ }^{[20][11]}$. The interdisciplinary team model consists of areas of, but not limited to, physical therapy, occupational therapy, speechlanguage pathology, special education, psychology, medicine, nursing, nutrition, and social work to guarantee its safety and effectiveness ${ }^{[15]}$.

Results from a dolphin-assisted therapy research shows changes in several aspects including communicative abilities, social-emotional behavior, and mother-child interaction, whereas many are short-termed and some are mild ${ }^{[9]}$. However, many researches carried out around dolphin-assisted therapy mostly focus on children with severe disabilities in general instead of specifically accentuating its effect on ASD children, thus its efficacy for autistic patients in particular may require further studies.

\section{Musical Intervention Therapy (MIT)}

Musical intervention therapy implements music and music activities for the foundation of therapeutic interventions ${ }^{[38]}$. This way of intervention primarily aims to initiate and sustain joint attention and among all music, improvisational music is a key element ${ }^{[4]}$. The context of the mentioned method evolves over time which makes it more flexible and individualized. Music and lyrics are composed before the session and usually presented by recording or a sung presentation ${ }^{[30]}$. Several researchers depict the process as "meet the child" in music that the participants are able to match and reflect their feelings in the played music ${ }^{[1]\left[{ }^{[2]}[25][41]\right.}$ in other words, music serves as an assisted way to help children expressing their emotions. In such a way, this way of intervention is highly childcentered in order for them to make personal connections with the music played by therapists ${ }^{[41]}$. The musical interaction mentioned above somehow also mimics a mother-infant non-verbal interaction where the reciprocity in rhythmic, melody and dynamic style is similar to the interaction between the therapist and children ${ }^{[33][28]}$ ${ }^{[36][37][41]}$. In general, MIT mostly provides significant improvement in reciprocal, interactive communication and play ${ }^{[42]}{ }^{[41]}$ though there are still participants who show negative results ${ }^{[30]}$, thus MIT may be considered as an effective CAM.

\section{Equine-Assisted Therapy}

There are various approaches under equine-assisted therapy (EAT) which includes therapeutic horseback riding and therapeutic horsemanship. EAT can provide many positive benefits in multiple perspectives including social, emotional, communicative, and physical domains. Physically, the rhythmic equine movements are beneficial for one's balance, coordination, posture, and muscle symmetry. Mentally, there is increasing evidence that suggests EAT can also improve participants' self-esteem, self-concept, and self-efficacy ${ }^{[19]}{ }^{[6]}$. According to the report, individuals who receive CAM interventions 
seldom publicly mention or discuss their experiences as it may suggest they suffer from some kind of disabilities. However, in the condition of therapeutic riding, individuals may be willing to share it with their friends. Moreover, some of the participants are willing to attend activities and look forward to it ${ }^{[19]}$. The changes that are mentioned above clearly indicate the social and language improvements brought by EAT, but existing researches are limited and small in scale. The physiological benefits of EAT seem widely accepted, but the pathways for improvements of participant's mental well-being remain relatively unknown. Like many other CAM interventions, individual differences should also be taken into consideration and many interference factors are not removed. Many researches implementing EAT are not specifically focused on ASD treatment, but a particular type of disability instead. Since ASD includes a wide range of disability and atypical behaviors, the information collected is not enough to fully prove and evaluate the efficacy of hippotherapy. Additionally, considering the cost for utilizing hippotherapy on a regular basis, its prevalence and benefits may be reevaluated.

\section{References}

[1] Alvin, J. Music Therapy for the Autistic Child. Oxford University Press, 1978.

[2] Alvin, J., Warwick, A. Music Therapy for the Autistic Child (2nd ed.). Oxford University Press, 1991.

[3] Baddeley, A. Working memory, Oxford University Press, Oxford, 1986.

[4] Bernard, S., Enayati, A., Redwood, L., Roger, H., Binstock, T. Autism: A novel form of mercury poisoning. Medical Hypotheses, 2001, 56(4): 462-471. https://doi.org/10.1054/mehy.2000.1281

[5] Biklen, D., Morton, M. W., Gold, D., Berrigan, C., Swaminathan, S. Facilitated communication. Topics in Language Disorders, 1992, 12(4): 1-28. https://doi.org/10.1097/00011363-199208000-00003

[6] Borgi, M., Loliva, D., Cerino, S., Chiarotti, F., Venerosi, A., Bramini, M., Nonnis, E., Marcelli, M., Vinti, C., De Santis, C., Bisacco, F., Fagerlie, M., Frascarelli, M., Cirulli, F. Effectiveness of a Standardized Equine-Assisted Therapy Program for Children with Autism Spectrum Disorder. Journal of Autism and Developmental Disorders, 2015, 46(1): 1-9. https://doi.org/10.1007/s10803-015-2530-6

[7] Braman, B. J., Brady, M. P., Linehan, S. L., Williams, R. E. (1995). Facilitated Communication for Children with Autism: An Examination of Face Validity. Behavioral Disorders, 21(1), 110-118. https://doi.org/10.1177/ 019874299502100102
[8] Brantl, V., Teschemacher, H., Bläsig, J., Henschen, A., Lottspeich, F. Opioid activities of $\beta$-casomorphins. Life Sciences, 1981, 28(17): 1903-1909. https://doi.org/10.1016/0024-3205(81)90297-6

[9] Breitenbach, E., Stumpf, E., Fersen, L. V., Ebert, H. V. Dolphin-Assisted Therapy: Changes in Interaction and Communication between Children with Severe Disabilities and Their Caregivers. Anthrozoös, 2009, 22(3): 277-289. https://doi.org/10.2752/175303709X457612

[10] Brudnak, M. A., Rimland, B., Kerry, R. E., Dailey, M., Taylor, R., Stayton, B., Waickman, F., Waickman, M., Pangborn, J., Buchholz, I. Enzyme-based therapy for autism spectrum disorders - Is it worth another look? Medical Hypotheses, 2002, 58(5): 422-428. https://doi.org/10.1054/mehy.2001.1513

[11] Foxx, R. M. (n.d.). Get a Copy Find a copy in the library AbeBooks $\$ 1.99$ Barnes \& Noble $\$ 26.23$ Better World Books Increasing behaviors of persons with severe retardation and autism.

[12] Galaburda, A. M. From Reading to Neurons. MIT Pression, 1989.

[13] Horvath, K., Stefanatos, G. Improved social and language skills after secretin administration in autistic spectrum disorders. Journal of the Association for Academic Minority Physicians: the official publication of the Association for Academic Minority Physicians, 1998.

[14] Krishnaswami, S., McPheeters, M. L., Veenstra-VanderWeele, J. A Systematic Review of Secretin for Children With Autism Spectrum Disorders. PEDIATRICS, 2011, 127(5): e1322-e1325. https://doi.org/10.1542/peds.2011-0428

[15] Kurtz, L. A., Dowrick, P. W., Levy, S. E., Batshaw, M. L. (Eds.). Handbook of Developmental Disabilities. Aspen Publishers, 1996.

[16] Levy, S. E., Hyman, S. L. Novel treatments for autistic spectrum disorders. Mental Retardation and Developmental Disabilities Research Reviews, 2005, 11(2): 131-142. https://doi.org/10.1002/mrdd.20062

[17] Lewis, M., Harwitz, M. The Meaning of an Orienting Response: a Study in the Hiearchical Order of Attending. ETS Research Bulletin Series, 1969(1): i-40. https://doi.org/10.1002/j.2333-8504.1969.tb00574.x

[18] Lightdale, J. R., Hayer, C., Duer, A., Lind-White, C., Jenkins, S., Siegel, B., Elliott, G. R., Heyman, M. B. Effects of Intravenous Secretin on Language and Behavior of Children With Autism and Gastrointestinal Symptoms: A Single-Blinded, Open-Label Pilot Study. Pediatrics, 2001, 108(5): e90. https://doi. org/10.1542/peds.108.5.e90 
[19] Macauley, B. L., Gutierrez, K. M. The Effectiveness of Hippotherapy for Children With Language-Learning Disabilities. Communication Disorders Quarterly, 2004, 25(4): 205-217. https://doi.org/10.1177/15257401040250040501

[20] Miller, L. K. (with Miller, L. K.). Principles of Everyday Behavior Analysis. Brooks/Cole Publishing Company, 1980.

[21] Moskowitz, H., \& Lohmann, W. Auditory Threshold for Evoking an Orienting Reflex in Mongoloid Patients. Perceptual and Motor Skills, 1970, 31(3): 879882. https://doi.org/10.2466/pms.1970.31.3.879

[22] Mudford, O. C., Cross, B. A., Breen, S., Cullen, C., Reeves, D., Gould, J., Douglas, J. Auditory Integration Training for Children With Autism: No Behavioral Benefits Detected. American Journal on Mental Retardation, 2000, 105(2): 118. https://doi.org/10.1352/0895-8017(2000)105<0118: AITFCW $>2.0 . \mathrm{CO} ; 2$

[23] Munasinghe, S. A., Oliff, C., Finn, J., Wray, J. A. Digestive Enzyme Supplementation for Autism Spectrum Disorders: A Double-Blind Randomized Controlled Trial. Journal of Autism and Developmental Disorders, 2010, 40(9): 1131-1138. https://doi.org/10.1007/s10803-010-0974-2

[24] Nathanson, D. E. Long-Term Effectiveness of Dolphin-Assisted Therapy for Children with Severe Disabilities. In D. Nathanson (Author), Anthrozoös: multidisciplinary journal of the interactions of people and animals, 1998: 22-32. https://doi.org/10.1080/08927936.1998.11425084

[25] Nordoff, P., Robbins, C. Creative Music Therapy. The John Day Company, 1977.

[26] NYBERG, F., Lleberman, H., LINDSTRÖM, L. H., LYRENÄS, S., Koch, G., Terenius, L. Immunoreactive $\beta$-Casomorphin-8 in Cerebrospinal Fluid From Pregnant and Lactating Women: Correlation With Plasma Levels*. The Journal of Clinical Endocrinology \& Metabolism, 1989, 68(2): 283-289. https://doi.org/10.1210/jcem-68-2-283

[27] Panksepp, J. A neurochemical theory of autism. Trends in Neurosciences, 1979, 2: 174-177. https://doi.org/10.1016/0166-2236(79)90071-7

[28] Pavlicevic, M. Dynamic Interplay in Clinical Improvisation. Journal of British Music Therapy, 1990, 4(2): 5-9. https://doi.org/10.1177/135945759000400202

[29] Rayner, K., Murphy, L. A., Henderson, J. M., Pollatsek, A. Selective attentional dyslexia. Cognitive Neuropsychology, 1989, 6(4): 357-378. https://doi.org/10.1080/02643298908253288
[30] Simpson, K., Keen, D. Music Interventions for Children with Autism: Narrative Review of the Literature. Journal of Autism and Developmental Disorders, 2011, 41(11): 1507-1514. https://doi.org/10.1007/s10803-010-1172-y

[31] Sokolov, Y. Perception and the Conditioned Reflex. MacMillan, 1963.

[32] Solman, R. T., Cho, H.-S., Daint, S. J. Colour-mediated grouping effects in good and disabled readers. Ophthalmic and Physiological Optics, 1991, 11(4): 320-327. https://doi.org/10.1111/j.1475-1313.1991.tb00232.x

[33] Stern, D. N. (n.d.). The Interpersonal World Of The Infant: A View from Psychoanalysis and Developmental Psychology.

[34] Summary of Autism Spectrum Disorder (ASD) Prevalence Studies [Chart]. (n.d.). Centers for Disease Control and Prevention.

https://www.cdc.gov/ncbddd/autism/documents/ASDPrevalenceDataTable2016-508.pdf

[35] Sun, Z., Cade, J. R. A Peptide Found in Schizophrenia and Autism Causes Behavioral Changes in Rats. Autism, 1999, 3(1): 85-95. https://doi.org/10.1177/1362361399003001007

[36] Trevarthen, C. Intrinsic motives for companionship in understanding: Their origin, development, and significance for infant mental health. Infant Mental Health Journal, 2001, 22(1-2): 95-131. https://doi.org/10.1002/1097-0355(200101/04)22:1< 95::AID-IMHJ4>3.0.CO;2-6

[37] Trevarthen, C. Autism, sympathy of motives and music therapy. Enfance, 2002: 86-99.

[38] Umbarger, G. T. State of the Evidence Regarding Complementary and Alternative Medical Treatments for Autism Spectrum Disorders. Education and Training in Developmental Disabilities, 2007, 42: 437 447.

[39] White, J. F. Intestinal Pathophysiology in Autism. Experimental Biology and Medicine, 2003, 228(6): 639-649. https://doi.org/10.1177/153537020322800601

[40] Whyte, J. Attentional processes and dyslexia. Cognitive Neuropsychology, 1994, 11(2): 99-116. https://doi.org/10.1080/02643299408251969

[41] Wigram, T., Gold, C. Music therapy in the assessment and treatment of autistic spectrum disorder: Clinical application and research evidence. Child: Care, Health and Development, 2006, 32(5): 535542. https://doi.org/10.1111/j.1365-2214.2006.00615.x

[42] Wimpory, D., Chadwick, P., Nash, S. Brief report: Musical interaction therapy for children with autism: 
An evaluative case study with two-year follow-up. Journal of Autism and Developmental Disorders, 1995, 25(5): 541-552.

https://doi.org/10.1007/bf02178299

[43] Zeaman, D., \& House B. J. (n.d.). The Role of Attention in Retardate Discrimination Learning. Handbook of Mental Deficiency.
[44] Zhang, J., Mayton, M. R., \& Wheeler, J. J. Effectiveness of Gluten-Free and Casein-Free Diets for Individuals with Autism Spectrum Disorders: An Evidence-Based Research Synthesis. Education and Training in Autism and Developmental Disabilities, 2013, 48: 276-287. 